\title{
Cytomorphological Studies in the Genus Linum
}

\author{
A. Seetharam and D. Srinivasachar ${ }^{2}$
}

Indian Agricultural Research Institute, New Delhi-12, India

Received March, 19, 1971

\section{Introduction}

In the genus Linum, although 35 species besides Linum usitatissium have been listed (Darlington and Wylie 1955, Rajan and Thakare 1959) interspecific hybridization between not more than a dozen species have been attempted. Several of the wild species of Linum possess many agronomically valuable genes such as resistance to diseases and drought, winter hardiness, etc., besides possessing an unexplored reservoir of genetic variability like variation in oil quality (Plessers 1966, Yermanos et al. 1966) which may be of great value if transferred to the cultivated species. Studies on interspecific hybridization provide an answer to the question how far this untapped reservoir of germplasm could be exploited. Incidentally, interspecific hybridization will also tell us about the inter-relationship between the species. A thorough study of species and species-hybrids are essential if they are to be successfully utilized in a breeding programme.

Several species of Linum both cultivated and wild were crossed in different combinations and the hybrids were studied to establish inter-relationship between them and to see how far these species could be utilized in the improvement of cultivated linseed. The present study is a detailed account of cytomorphological behaviour of some of the hybrids.

\section{Materials and methods}

The following species and species hybrids were used in the present study:

$\begin{array}{ll}\text { 1. L. usitatissimum cultivar N.P. (R.R.) } 9 & \text { 13. L. floccosum } \times \text { L. strictum }\end{array}$

2. L. usitatissimum, cultivar N.P. (R.R.) 200 14. L. floccosum $\times$ N.P. (R.R.) 200

3. L. angustifolium

15. L. floccosum $\times$ L. crepetans

4. L. floccosum

16. L. hirsutum $\times$ L. crepetans

5. L. africanum

17. L. hirsutum $\times$ N.P. (R.R.) 200

6. L. strictum

18. L. tenue $\times$ N.P. (R.R.) 9

7. L. tenue

19. L. tenue $\times$ N.P. (R.R.) 200

8. L. hirsutum

20. L. africanum $\times$ N.P. (R.R.) 200

9. L. palliscence

10. L. angustifolium $\times$ N.P. (R.R.) 9

21. L. africanum $\times$ L. strictum

11. L. angustifolium $\times$ N.P. (R.R.) 200

22. L. palliscence $\times$ N.P. (R.R.) 200

12. L. angustifolium $\times$ L. strictum

23. L. palliscence $\times$ L. hirsutum

Present address: 1 Assistant Cytogeneticist, UAS, Bangalore-24, India.

2 Geneticist, Division of Genetics, IARI, New Delhi-12, India. 
All the species and hybrids have $2 n=30$ chromsomes in their somatic cells. Except $L$. hirsutum, $L$. palliscence, $L$. crepetans, the seeds of which were received from the plant introduction substation, Simla, India, those of the other species were already available at I.A.R.I., New Delhi. All the crosses were made under controlled conditions in a glass house. The parents and the $F_{1}$ hybrids obtained from the crosses were raised in pots and they were used for the study of morphology and meiosis. For meiotic study, the simple propiono carmine smear method was followed (Swaminathan et al. 1954).

\section{Results}

\section{Comparative morphological characters of Linum species and their hybrids under} study

The salient features of external morphology of the $F_{1}$ hybrids were compared with those of their parents. Emphasis was laid on the important key characters both vegetative and reproductive of diagnostic value in describing the species and hybrids. The data are presented in Table 1. Considerable variation was observed for different characters in different species studied. The species L. strictum seems to be important from the point of view of the number of primary tillers. All the species including cultivated species had 7-9 primary tillers per plant in contrast to L. strictum which on an average had 17. All the hybrids grew vigorously and they were intermediate between the two parents for most of the morphological characters studied (see Table 1). However some interspecific hybrids showed hybrid vigour in respect of characters like plant height, number of primary tillers and number of secondary branches per primary tiller etc.

\section{Comparative cytology of Linum species and hybrids under study}

Meiosis in the pollen mother cells of hybrids and their parents was studied in detail with reference to the pairing behaviour of the chromosomes. Pairing between the homologous chromosomes in all the species was found to be complete and normal at metaphase I. The bivalents showed mostly either one chiasma or two chiasmata. The later stages of meiosis also were normal resulting in high percentage of fertile pollen and good seed setting.

Most of the interspecific hybrids showed varying degrees of pollen sterility ranging from 10-40 per cent. But they showed normal meiosis with 15 bivalents at metaphase I (Fig. 1). Inspite of normal meiosis, all the interspecific hybrids showed reduced pollen and seed fertility presumably due to genetic imbalance. However, the hybrids, L. palliscence $\times$ N.P. (R.R.) $200, L$. palliscence $\times$ L. strictum, $L$. floccosum $\times$ N.P. (R.R.) 200, L. floccosum $\times$ L. strictum and L. floccosum $\times L$. africanum showed presence of a single quadrivalent in 35.0 to 40.0 per cent of their meiotic cells (Figs. 2-6). These hybrids also showed high pollen sterility ranging from 24.0 to 36.0 per cent.

Chiasma frequency: The study of meiosis in the species and their hybrids did not reveal any marked difference in chromosome pairing except for the presence of a quadrivalent in some hybrids. There are several such instances reported in litera- 
ture, where, eventhough pairing is normal in interspecific crosses, the chiasma frequency of the hybrids deviates considerably from the parents depending upon the relative affinities of the parental species.

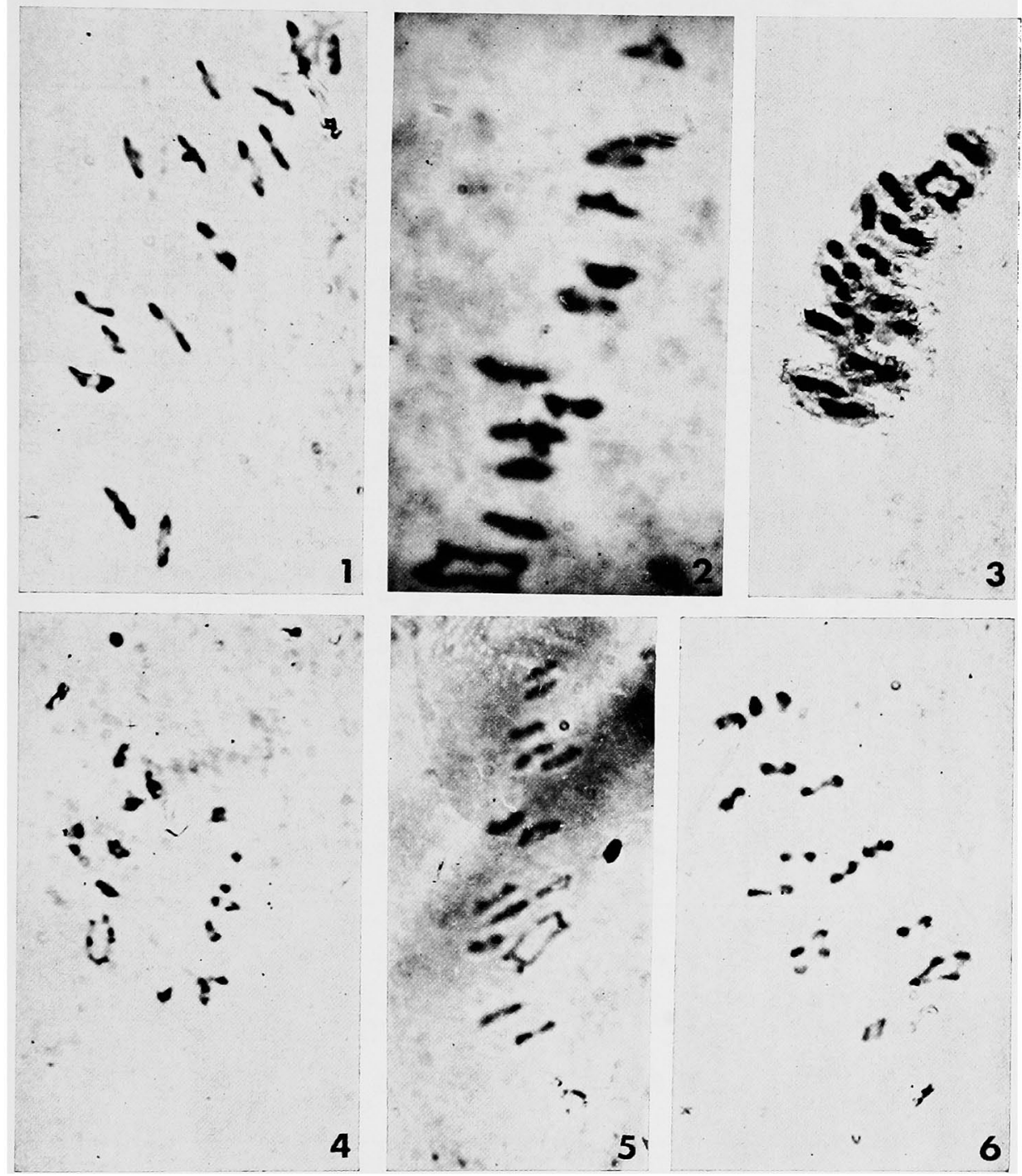

Fig. 1-6. 1, normal cell of Linum usitatissimum with 15 bivalents at MI. $\times 1500 . \quad 2$, L. palliscence $\times$ N.P. (R.R) 200. MI with 13 II and 1 IV. $\times 2000$. 3, L. palliscence $\times$ L. strictum. MI with $13 \mathrm{II}$ and 1 IV. $\times 1500$. 4, L. floccosum $\times$ N.P. (R.R) 200 . MI with 13 II and 1 IV. $\times 1500$. 5, L. floccosum $\times$ L. strictum. MI with 13 II and 1 IV. $\times 1500 . \quad 6$, L. floccosum $\times$ L. africanum with $13 \mathrm{II}$ and $1 \mathrm{IV} . \quad \times 1500$.

In the present study, chiasma frequency was determined in all the hybrids and their parents with the object of finding how they behave with regard to this character. It is evident from Table 2 that there is considerable difference in the chiasma frequency of the various species. The maximum chiasma frequency was in L. crepetans 


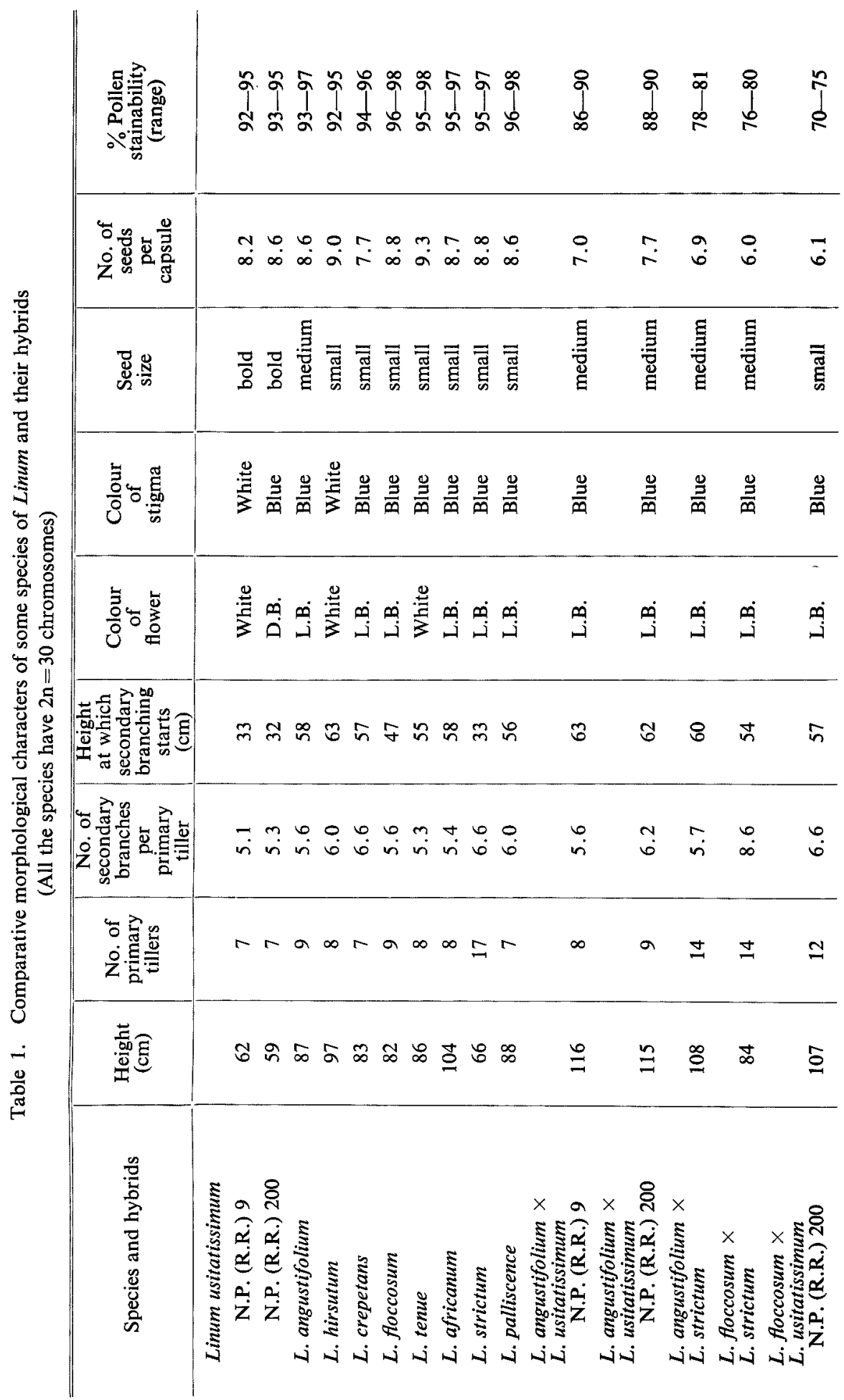




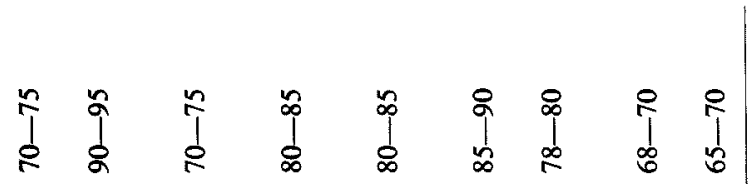

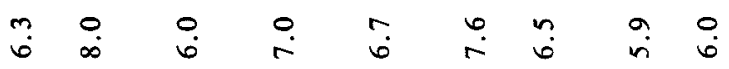

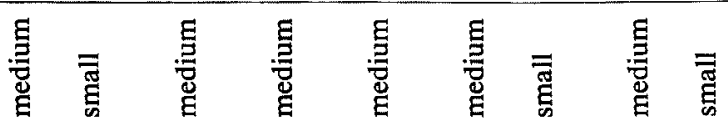

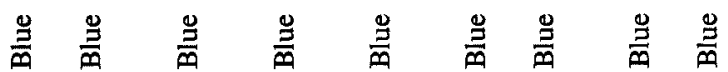

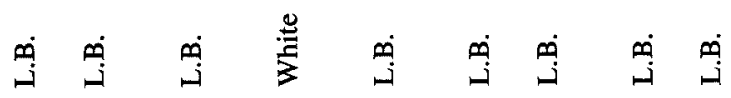

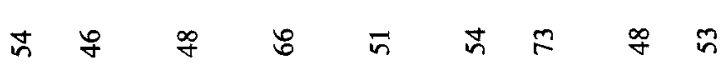

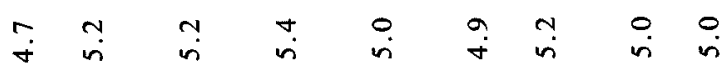

$$
\begin{aligned}
& =r \quad \infty \quad 0 \quad a \simeq \infty \quad \infty \\
& \text { 吉 }
\end{aligned}
$$

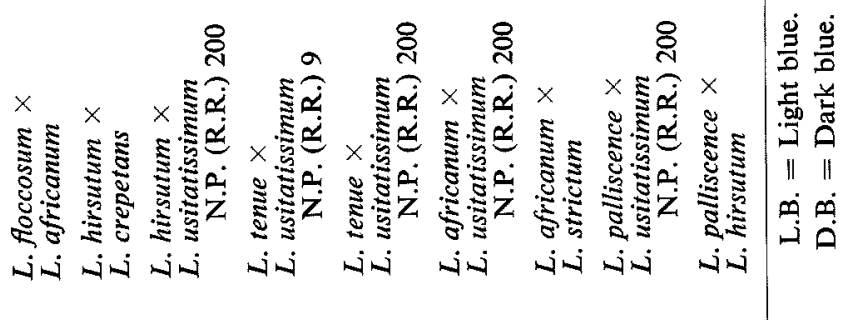


with $23.40 \pm 0.203$ chiasmata per cell and the lowest in $L$. hirsutum with $22.00 \pm 0.253$ chiasmata per cell. In rest of the species it was ranging between 22.00 and 23.40 chiasmata per cell. In the species $L$. usitatissimum the mean chiasma per cell was $22.53 \pm 0.098$ and $22.80 \pm 0.193$ in the varieties N.P. (R.R.) 9 and N.P. (R.R.) 200 respectively.

Table 2. Comparative chiasma frequency in some interspecific hybrids and their parents

\begin{tabular}{|c|c|c|c|c|c|c|}
\hline \multirow{2}{*}{ Species and hybrids } & \multirow{2}{*}{$\begin{array}{c}\text { No. of } \\
\text { cells } \\
\text { analysed }\end{array}$} & \multicolumn{2}{|c|}{ Bivalents with } & \multirow{2}{*}{$\begin{array}{r}\text { Total } \\
\text { Xta }\end{array}$} & \multirow{2}{*}{$\begin{array}{l}\text { Average Xta } \\
\text { per cell }\end{array}$} & \multirow{2}{*}{$\begin{array}{l}\text { Test of } \\
\text { significance }\end{array}$} \\
\hline & & $1 \mathrm{Xma}$ & $2 X t a$ & & & \\
\hline $\begin{array}{l}\text { Linum ustitatissimum } \\
\text { N.P. (R.R) } 9 \\
\text { N.P. (R.R) } 200\end{array}$ & $\begin{array}{l}40 \\
40\end{array}$ & $\begin{array}{l}299 \\
288\end{array}$ & $\begin{array}{l}301 \\
312\end{array}$ & $\begin{array}{l}901 \\
912\end{array}$ & $\begin{aligned} 22.53 & \pm 0.095 \\
22.80 & \pm 0.193\end{aligned}$ & \\
\hline L. angustifolium & 40 & 289 & 311 & 911 & $22.72 \pm 0.074$ & \\
\hline L. strictum & 30 & 224 & 226 & 676 & $22.53 \pm 0.109$ & \\
\hline L. tenue & 40 & 301 & 299 & 899 & $22.41 \pm 0.096$ & \\
\hline L. hirsutum & 30 & 240 & 210 & 660 & $22.00 \pm 0.253$ & \\
\hline L. crepetans & 40 & 264 & 336 & 936 & $23.40 \pm 0.203$ & \\
\hline L. africanum & 30 & 206 & 244 & 694 & $23.13 \pm 0.163$ & \\
\hline $\begin{array}{l}\text { L. angustifolium } \times \\
\text { L. strictum }\end{array}$ & 30 & 227 & 223 & 673 & $22.43 \pm 0.072$ & $\mathrm{~F}_{1}=\mathrm{P}_{1}=\mathrm{P}_{2}$ \\
\hline $\begin{array}{l}\text { L. tenue } \times \\
\text { L. ustitatissimum } \\
\quad \text { N.P. (R.R) } 9\end{array}$ & 30 & 222 & 228 & 678 & $22.60 \pm 0.124$ & $\mathrm{~F}_{1}=\mathrm{P}_{1}=\mathrm{P}_{2}$ \\
\hline $\begin{array}{l}\text { L. angustifolium } \times \\
\text { L. usitatissimum } \\
\text { N.P. (R.R) } 9\end{array}$ & 30 & 213 & 237 & 687 & $22.90 \pm 0.094$ & $\mathbf{F}_{1}=\mathbf{P}_{1}=\mathbf{P}_{2}$ \\
\hline $\begin{array}{l}\text { L. hirsutum } \times \\
\text { L. crepetans }\end{array}$ & 30 & 219 & 231 & 681 & $22.78 \pm 0.253$ & $\mathbf{F}_{\mathbf{1}}>\mathbf{P}_{\mathbf{1}} \quad \mathbf{F}_{1}<\mathbf{P}_{\mathbf{2}}$ \\
\hline $\begin{array}{l}\text { L. africanum } \times \\
\text { L. strictum }\end{array}$ & 30 & 238 & 212 & 662 & $22.07 \pm 0.189$ & $\mathbf{F}_{1}<\mathbf{P}_{1}$ and $\mathbf{P}_{2} \mathbf{P}_{1}>\mathbf{P}_{2}$ \\
\hline $\begin{array}{l}\text { L. tenue } \times \\
\text { L. usitatissimum } \\
\quad \text { N.P. (R.R) } 200\end{array}$ & 30 & 215 & 235 & 685 & $22.83 \pm 0.120$ & $\mathbf{F}_{1}=\mathbf{P}_{1}=\mathrm{P}_{2}$ \\
\hline $\begin{array}{l}\text { L. hirsutum } \times \\
\text { L. usitatissimum } \\
\text { N.P. (R.R) } 200\end{array}$ & 30 & 217 & 233 & 683 & $22.76 \pm 0.256$ & $F_{1}>P_{1} \quad P_{1}=P_{2}$ \\
\hline $\begin{array}{l}\text { L. angustifolium } \times \\
\text { L. usitatissimum } \\
\quad \text { N.P. (R.R) 200 }\end{array}$ & 30 & 218 & 232 & 682 & $22.73 \pm 0.053$ & $F_{1}=P_{1}=P_{2}$ \\
\hline
\end{tabular}

It is seen that in hybrids the chiasma frequency did not deviate significantly from their parents while in others it was much reduced. The hybrids L.africanum $\times$ L. strictum showed significant reduction in their mean chiasmata per cell. This seems to indicate that there is a restricted flow of genes between the species involved in the cross and they have diverged from each other to a greater degree than those in which there was a free flow of genes.

The chiasma frequency of the hybrids which had either L. floccosum or L. palliscence as one of their parents was also analysed. They showed significant reduction in their mean chiasma frequency than their parents (Table 2(a)). 


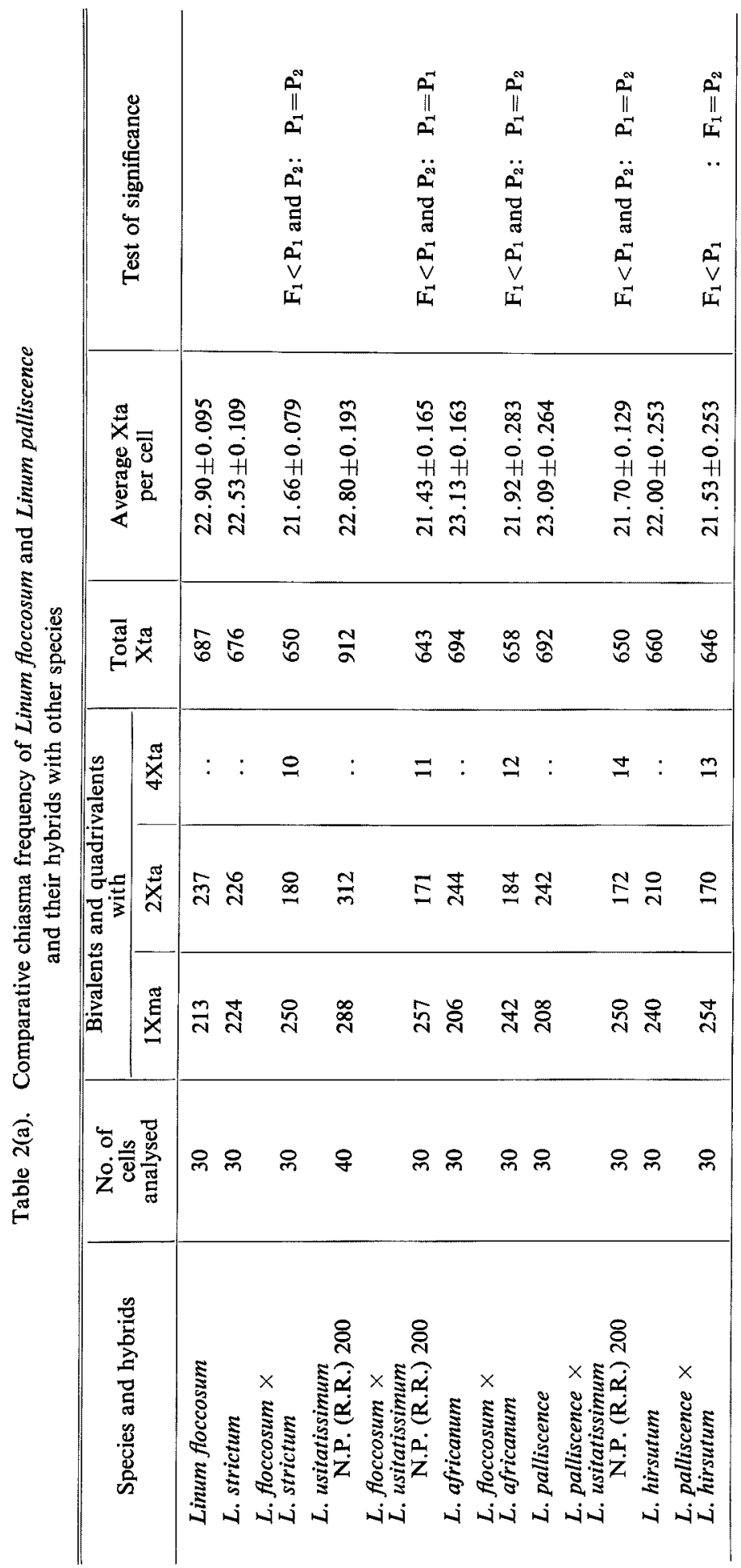




\section{Discussion}

The genus Linum to which L. usitatissimum belongs contains a number of species with varying chromosome numbers (McGregor 1960), the majority of which have $2 n=30$. In the present study eight species all having the same chromosome number $(2 n=30)$ were used mainly with the object of assessing the possibility of transferring some of their desirable characters to the cultivated species. The opportunity was also taken to study the interrelationships between these species.

The species were studied only for the important morphological characters of diagnostic value. While evaluating the various morphological characters it is seen that there is a considerable diversity in the habit of the sepecies. The species under consideration showed great diversity for characters like plant height, number of primary branches, number of secondary branches, flower colour and seed size.

The interspecific hybrids generally were intermediate for most of the morphological characters studied However, some of them exhibited hybrid vigour for characters like height, number of tillers etc. They also showed reduced seed and pollen fertility.

Systematic cytomorphological studies in the genus Linum are sporadic and the majority of earlier investigations in this genus were limited to the determination of somatic chromosome numbers. Meiosis in the hybrids studied here was basically normal and did not show any gross abnormality. It would appear therefore, that the role of gross structural changes in the differentiation of taxa is not significant. However, the presence of cryptic structural differences in the species cannot be ruled out.

Microsporogenesis was studied in all the species and their hybrids and usually 15 bivalents were found at diakinesis and metaphase I. Configurations higher than bivalents were not observed in any of the species. Studies on chiasma frequency showed that $L$. crepetans with a mean frequency of 23.40 per cell was significantly higher over the other species at metaphase I. L. hirsutum with a mean chiasma frequency of 22.00 per cell was significantly the lowest. The late meiotic stages in all the species were normal resulting in high percentage of fertile pollen and good seed setting. Study of meiosis in the interspecific hybirds did not reveal any conspicuous deviation in the pairing behaviour of chromosomes. They showed normal pairing at diakinesis and metaphase I with later stages also normal. However, the hybrids $L$. floccosum $\times$ N.P. (R.R.) 200, L. floccosum $\times$ L. africanum, L. floccosum $\times$ L. strictum, L. palliscence $\times$ N.P. (R.R.) 200, L. Palliscence $\times L$. hirsutum showed a quadrivalent in their meiotic cells suggesting that they differed from each other by the presence of a reciprocal translocation. These hybrids did show high pollen sterility ranging from 26 to 36 per cent.

Answer sought to the nature of differentiation between different species of the genus Linum by the study of chromosomal behaviour did not reveal any clear evidence. But such a study was not the complete solution for the problem in the light of Stebbins (1945) postulation that structural differences between the chromosomes would conceivably co-exist with a high degree of regular meiotic pairing and be- 
haviour of chromosomes. Moreover the hybrids showed varying degrees of sterility either genic or chromosomal. The presence of large structural differences can be usually detected by the study of pachytene pairing in meiosis. But in linseed pachytene analysis is difficult due to large number of very small chromosomes. As Stebbins (1945) pointed out cryptic structural differences between chromosomes could be detected by indirect evidences such as reduction in chiasmata. Since the cryptic structural differences may not be able to offer much hindrance to pairing between chromosomes concerned, meiosis would appear apparantly normal, but they may be able to effectively prevent the free exchange of genes located within or very close to such regions and reduce the chiasma frequency. Correlation between existence of cryptic structural differences and reduction in chiasma frequency has been shown in different crops (Shambhulingappa and Magoon 1963, Stephens 1950).

In the present study the chiasma frequency in the hybrids and the parents gave evidence for the presence of cryptic structural differences. Based on the chiasma frequency the interspecific hybrids have been grouped into two categories: 1) Those showing no significant deviation from their parents; and 2) those showing significant deviation from their parents.

The following hybrids showed no significant deviation in chiasma frequency from their parents:

L. angustifolium $\times$ L. strictum, L. tenue $\times$ N.P. (R.R.) 9, L. tenue $\times$ N.P. (R.R.) 200 , L. angustifolium $\times$ N.P. (R.R.) 9, L. angustifolium $\times$ N.P. (R.R.) 200, L. hirsutum $\times L$. crepetans, L. hirsutum $\times$ N.P. (R.R.) 200 . They showed normal meiosis. There was no reduction in the mean chiasma ferquency from those of their parents. However, the hybrids showed varying degrees of sterility ranging from 10 25 per cent.

These observations, therefore, strongly suggest that differentiation, if any, in these species is at the genic level as the sterility observed is genic rather than chromosomal. There is, however, the possibility that these species may also be harbouring cryptic structural differences as Stebbins (1938) found no correlation between structural differences and reduction in chiasma frequency and sterility in the genus Poeonia.

The hybrids, L. africanum $\times L$. strictum, L. floccosum $\times L$. strictum, $L$. floccosum $\times$ N.P. (R.R.) 200 , L. floccosum $\times$ L. africanum, L. palliscence $\times$ N.P. (R.R.) 200, L. palliscence $\times$ L. hirsutum showed significant reduction in chiasma frequency as compared to their parental species. These hybrids showed normal pairing at metaphase I with subsequent stages also being normal. The hybrids except $L$. africanum $\times L$. strictum showed occasionally a single quadrivalent in their meiotic cells. They also showed high pollen sterility ranging from $20-40$ per cent. The partial sterility and reduced chiasma frequency observed in the hybrids can be attributed to structural differences in the parental genomes (Stebbins $1945,1950)$ or to the action of different genetic factors which inhibit chromosome pairing. These structural changes may in themselves produce morphological variation. It thus appears diversification in these parental species has gone on at the structural level. 
Stephens (1961) classified interspecific hybrids (taking metaphase I pairing into consideration) into four categories:

Category I includes the interspecific hybrids but their behaviour is like those of the intervarietal ones where normal meiosis is followed by good fertility. In categories II and III the chromosome pairing at meiotic metaphase is normal. The evidence for cryptic structural differences in the category II is lacking while in category III it can be shown to exist by polyploidy test by taking preferential pairing into account. Category IV represents highly irregular meiosis with complete to partial failure of pairing accompanied by high sterility. It would be interesting to compare the above classification based on metaphase pairing with the hybrids of the present study. However, none of the hybrids in the present study fall under I and IV described above. Category II of Stephens (1961) can be considered equivalent to the hybrids which did not show any change in chiasma frequency but were accompanied by partial pollen sterility. Category III of Stephens can be equated to some extent with the present hybrids which showed reduced chiasma frequency as this provides an indirect evidence for the possible presence of cryptic structural differences.

\section{Summary}

With a view to finding out the inter-relationships between different 30 chromosome species of the genus Linum, 14 interspecific hybrids involving 8 species were obtained and studied morphologically and cytologically.

The interspecific hybrids were studied for salient morphological characters of agronomic importance such as tillering, height, number of secondary branches, seed size besides hybrid vigour and seed fertility. They were also studied for their chromosome pairing and chiasma frequency in the pollen mother cells.

The hybrids showed varying degrees of pollen sterility inspite of their chromosomes pairing and separating regularly. This indicated that the divergence of these species has progressed on either genic differentiation or cryptic structural differences. The species $L$. floccosum and $L$. palliscence differed from the rest in forming a single quadrivalent. This shows that these species differ from one another by a single reciprocal translocation.

Based on chiasma frequency all the hybrids can be grouped into two categories, those forming more or less equal number of chiasmata as the parental species and those forming less than the parents. Suitable interpretations are advanced to explain the reduction in chiasma frequency in some hybrids under study. Probable cytogenetical mechanisms underlying species differeniation in the genus Linum are discussed.

\section{Acknowledgement}

The financial assistance given to the senior author during the course of this work by the Indian Council of Agricultural Research, New Delhi, India, is greatfully acknowledged. 


\section{Literature cited}

Darlington, C.D. and Wylie, A.P. 1955. Chromosome Atlas of Flowering Plants. George Allen and Unwin Ltd., London, pp. 519.

McGregor, W. G. 1960. Research on oil seed flax in N. America. Field crop abstracts 13: 84, 87.

Plessers, A. G. 1966. The variation in fatty acid composition of the seed of Linum species. Can. J. Cyt. 8: $328-35$.

Rajan, S. S. and Thakare, R. G. 1959. Chromosome numbers of some Linum species. Indian Oil Seeds J. 3: 43.

Shambhulingappa, K. G. and Magoon, M. L. 1963. Cytomorphological studies in the genus Sorghum. Indian J. Genet. 23: 275-289.

Stebbins, G. L. 1938. Cytogenetic studies in Poeonia II. The cytology of the diploid species and hybrids. Genetica 23: 83-100.

- 1945. The cytological analysis of species hybrids. Bot. Rev. 11: 463-486.

- 1950. Variation and Evolution in Plants. Colambia Univ. Press, New York, pp. 643.

Stephens, S. G. 1950. The internal mechanisms of speciation in Gossypium. Bot. Rev. 16: 115149.

- 1961. Species differentiation in relation to crop improvement. Crop Science 1: 1-5.

Swaminathan, M. S., Magoon, M. L. and Mehra, K. L. 1954 . A simple propiono carmine smear method for plants with small chromosomes. Indian J. Genet. 14: 87-90.

Yermanos, D. M. Beard, B. H., Gill, K. S. and Anderson, M. P. 1966. Fatty acid composition of seed oil of wild species of Linum. Agron. J. 58: 30-32. 